\title{
Memorias trasformadoras: el arte político de la reconstrucción del tejido social en Chalán y Ovejas, Sucre ${ }^{27}$
}

\author{
Transformative memories: the political art of rebuilding the social \\ construction in Chalan y Ovejas, Sucre
}

Nathalia Castaño Feria ${ }^{1}$ y Diana Carolina García Giraldo ${ }^{*}$
(1) Universidad de Caldas - Manizales - Colombia, diana.261415100@ucaldas.edu.co
(2) Universidad de Caldas - Manizales - Colombia, carolina-522@hotmail.com
* Autor a quien se dirige la correspondencia

\section{Resumen}

En contextos históricamente permeados por el conflicto armado interno se hace pertinente la construcción de proyectos e investigaciones abrazados y pensados desde y con las comunidades. El presente artículo de investigación está tejido con el objetivo de comprender el tránsito de unas memorias centradas en hechos victimizantes hacia unas memorias transformadoras, por medio del arte político como estrategia y desde el enfoque de la Investigación Acción Participante (IAP), para aportar así al reconocimiento de las resistencias cotidianas agenciadas por las comunidades de los municipios de Chalán y Ovejas en el departamento de Sucre, Colombia.

Palabras Clave: conflictos; resolución de conflictos; memoria colectiva.

\section{Abstract}

In contexts historically permeated by the internal armed conflict, the construction of projects and research embraced and thought from and in communities becomes relevant. This research article is woven with the aim of understanding the transit of memories focused on victimizing events towards transformative memories, through political art as a strategy and from the approach of Participating Action Research (IAP), to contribute in this way. to the recognition of the daily resistances organized by the communities of the municipalities of Chalan and Ovejas in the department of Sucre, Colombia.

Keywords: conflicts; conflict resolution; collective memory.

27 Este artículo de investigación científica hace parte del proyecto macro "Hilando capacidades políticas para las transiciones en los territorios", inscrito en la Vicerrectoría de Investigación y Posgrados de la Universidad de Caldas, con el Código SIGP 57729. Fecha de inicio junio de 2018, vigencia hasta el año 2022. 


\section{Introducción}

Colombia es un territorio de memoria y vida. Fragmentado por la muerte y resistente al olvido y a la violencia es, entre montañas, ríos y mares que crece la esperanza y la utopía de construir paz, la cual emerge como un compromiso político y ético frente a un contexto que ha enfrentado la crueldad del conflicto armado y que ha permeado y quebrantado por varias décadas el tejido social y natural indiscriminadamente.

Tras la reciente firma de los acuerdos de paz ${ }^{28}$ entre el Gobierno y las FARC-EP ${ }^{29}$, el país entero está sumido en una coyuntura política, económica, social y cultural que exige retos para la transición hacia la paz; sin embargo, es una búsqueda de hacer cumplir el derecho de vivir en paz en la que diferentes grupos armados como ELN (Ejército de Liberación Nacional), AUC (Autodefensas Unidas de Colombia), CRS (Corriente de Renovación Socialista), Movimiento Armado "Quintín Lame" (MAQL), el Movimiento 19 de Abril (M-19), entre otros, ya han participado de negociaciones en las que se destacan aspectos favorables y desfavorables en los procesos de paz. El derecho a esta supone una responsabilidad ética y política desde las esferas íntimas y públicas que habitamos como ciudadanas y ciudadanos, así como el compromiso desde la academia, desde la institucionalidad y desde la sociedad en general.

La reconstrucción del tejido social implica un compromiso permanente con las comunidades, es por eso que se hace pertinente construir el conocimiento desde las múltiples voces y diversidades para que las comunidades se reconozcan y visibilicen como tejedoras y tejedores de paz.

El compromiso de la academia y las diferentes dependencias del Estado no debe estar reducida a los discursos, por el contrario, se hace necesario la permanencia en los territorios y el trabajo directo con las comunidades, es por ello que se debe trabajar en creación de estrategias novedosas y alternativas que permitan a las universidades, Fuerzas Armadas de Colombia y entidades gubernamentales y no gubernamentales, construir conocimiento desde las experiencias gestadas por las comunidades, las organizaciones sociales y los líderes, en la reconstrucción del tejido social, reparación y no repetición, como directrices del quehacer ético y político, consagrados en la Ley $1448^{30}$ de 2011, y también del acuerdo de paz que se viene implementando en Colombia desde el año 2016. Derecho consagrado en el Artículo 22 de la Constitución Política de Colombia de 1991.

En el presente artículo hablaremos de las experiencias tejidas desde las múltiples voces de las comunidades de Chalán y Ovejas, territorio de Montes de María, en horizontes de construir memorias transformadoras mediante el arte político como herramienta movilizadora, transversalizada por la metodología de IAP (Investigación, Acción Participación), buscando cimentar bases fuertes para la no repetición y tejiendo

28 El inicio de la negociación tuvo lugar en Oslo y La Habana, Cuba, durante el año 2012, bajo el gobierno del presidente Juan Manuel Santos. El día 26 de septiembre se firmó en Cartagena el acuerdo final de paz. Finalmente, el 24 de noviembre, tras algunas modificaciones en el Congreso, se pactaron cambios al acuerdo final y lo firman el expresidente Juan Manuel Santos y Rodrigo Londoño, antes comandante Timochenko, en el teatro Colón.

29 En la actualidad, desde el año 2017, son un partido político denominado "Fuerza Alternativa Revolucionaria de Común".

30 Ley 1448 de 2011: Por la cual se dictan medidas de atención, asistencia y reparación integral a las víctimas del conflicto armado interno y se dictan otras disposiciones. 
la reparación colectiva desde la voz de las comunidades y los diferentes actores que convergen en los territorios.

\section{Algunas precisiones conceptuales sobre memorias transformadoras}

La memoria, como idea, remite necesariamente a una experiencia del pasado, con unos hechos lejanos o cercanos que son significativos para quien los recuerda. En este aspecto, vale aclarar que, si bien el recuerdo puede darse de manera individual, esta no se convierte en propiedad o su uso es meramente individual, pues en el mismo acto de rememorar la experiencia es tejida en un contexto histórico y compartida en una esfera pública, con otros, entre otros. En este sentido, la memoria se construye como un acto político y éticamente compartido y no es individual, como comúnmente suele creerse.

Las experiencias traídas al presente son presentadas es un territorio específico, porque son conmemoradas, atesoradas, recobradas y, por otro lado, se encuentran dotadas de expectativas porque permiten tejer un horizonte que servirá de guía y construcción para pensar en un futuro. Podría considerarse, por una parte, que el futuro se sitúa fuera de la memoria y que pertenece únicamente al plano de la expectativa, a lo subjetivo, a lo inenarrable e indescifrable. Sin embargo, de otro lado y siendo complementario con lo anterior, "el futuro no aparece por fuera de la memoria, más bien se introduce en la dimensión de la esperanza, involucra una novedad, involucra anhelo e imaginación" (Jefferson, s, f, p.2).

En el plano de lo político y lo académico se ha pensado desde múltiples perspectivas el concepto de la memoria, esto lleva a que su nombre esté pasando por conceptos como: memoria institucional (oficial), memoria cultural (politización de la cultura), memoria histórica (relato restringido y homogenizante), memoria democrática (narrativa plural), memoria reivindicativa (desestigmatización). (Jefferson, s, f, p.2). Por último, se ha venido construyendo una nueva noción de memoria que va más allá de los hechos victimizantes y permite resignificar de manera alternativa el pasado, por ello, la noción de memoria transformadora abordada desde las construcciones realizadas por Jefferson Jaramillo Marín ${ }^{31}$, que, junto a la Red Paz, ha propuesto esta categoría como una elección de vida y resistencia ante el dolor y la injusticia.

Desde las memorias transformadoras se concibe el recuerdo como un acto político que permite en los contextos en medio de conflictividades buscar alternativas para transitar del dolor al reconocimiento de las capacidades como la resistencia, la solidaridad/ cooperación, la organización/afiliación y la confianza/protección, buscando que la memoria no sea reconocida únicamente desde el dolor y los hechos victimizantes ocurridos en sus territorios, sino que, por el contrario, la memoria permita tejer nuevas comprensiones alrededor de los hechos ocurridos, de las capacidades políticas que han hilado de manera individual, colectiva y comunitaria.

En este sentido, la memoria individual, colectiva y comunitaria posibilitan nuevos escenarios políticos y sociales, además, revitaliza y visibiliza múltiples capacidades políticas que han quedado olvidadas en la rutinización de lo cotidiano. Tales nuevos

31 El cual en un trabajo colaborativo con la Pontificia Universidad Javeriana (departamentos de Antropología y Sociología), la Unidad de Atención y Reparación Integral a las Víctimas del conflicto, y Redepaz en el marco del "proceso de caracterización del daño y construcción del plan de reparación colectiva para esta organización" (Jefferson, s, f, p.6). 
escenarios transforman los relatos hegemónicos sobre lo ocurrido y brindan a la vez una nueva comprensión identitaria de las comunidades, ya que, como nos dice Elizabeth Jelin, en los trabajos de la memoria:

Aun en los momentos más «individuales». "Nunca estamos solos», uno no recuerda solo sino con la ayuda de los recuerdos de otros y con los códigos culturales compartidos, aun cuando las memorias personales son únicas y singulares. [...] el núcleo de cualquier identidad individual o grupal está ligado a un sentido de permanencia (de ser uno mismo, de mismidad) a lo largo del tiempo y el espacio. Poder recordar y rememorar algo del propio pasado es lo que sostiene la identidad. (Jelin, 2002, pp. 20-25)

Estas memorias entretejidas han permitido hilar desde el pasado a la continuidad del presente nuevas formas de comprender, enunciar y visibilizar los escenarios cotidianos, el escenario de lo simbólico, en los que las formas de ser, habitar y pensar configuran nuevas interpretaciones sobre la violencia y exige a viva voz, cuerpo y espacio mandatos de verdad, justicia y paz.

La memoria es un vehículo de transformación no solo en el presente, sino una espiral que implica un constante ir y venir entre los hechos ocurridos y las resistencias históricas, de ahí que no debe ser entendida como un proceso lineal de sucesos y experiencias, sino como un constante tránsito entre pasado y futuro, construida a múltiples voces y sentires, por lo que la memoria "es una práctica social en tensión" (Jaramillo, 2014, p. 2). En este sentido, implica una reflexión en el presente en aras de proyectarse como comunidades políticamente activas en el ejercicio de formulación de políticas públicas, veeduría y conocimiento pleno de sus derechos y responsabilidades como ciudadanas y ciudadanos políticos y de derechos.

La memoria se convierte en un elemento fundamental en la reconstrucción de la historia y en el proceso de transición, aportando a la verdad y no repetición en las comunidades. Es necesario hacer pública la verdad desde múltiples voces y lenguajes, a través del arte, los diálogos públicos, entre otros; "distintos artefactos, vehículos culturales y recursos políticos, a través de los cuales las memorias del conflicto son narradas, exhibidas, representadas, archivadas o administradas en el espacio público" (Jaramillo, 2014, p. 1). Al entretejer de manera participativa y plural los espacios, cuerpos y recuerdos, se posibilita una apertura en el espacio - tiempo al diálogo y a la confluencia de sentidos, pensamientos y prácticas que van desde expresiones religiosas y éticas hasta políticas y culturales como símbolos de reivindicación social y colectiva, frente a la violencia y el silencio.

La memoria transformadora se puede concebir como un eje central de luchas por los derechos humanos, también para desmitificar las historias hegemónicas sobre los territorios, contadas a una única voz y permitiendo de esta manera resignificar los silencios. Es por ello que la memoria debe tener un componente contextual y plural, para comprender las dinámicas de los territorios y sus cambios a lo largo de su historicidad. 
"La memoria es un recurso político "movilizador" de la experiencia pasada y presente, que "produce" efectos de realidad hacia el futuro. En ese sentido, hablamos del potencial transformador de la memoria" (Jaramillo, 2014, p. 3), ya que posibilita un encuentro de múltiples voces que deciden tejer sobre sus experiencias anhelos de cambio, de no repetición, reconociéndose en los otros, intentado sanar colectivamente, dignificando sus historias de vida y resistencia y contribuyendo a desdibujar los estigmas que recaen sobre la mayoría de territorios históricamente afectados por el conflicto armado, "la memoria ancla en espacios y permite sanarlos cuando estos han sido fracturados. Es decir, hay un potencial sanador y transformador de fracturas localizadas en cuerpos, en naturalezas, en geografías. Además, la memoria ayuda en la construcción de una ciudadanía plural, intergeneracional, intercultural.” (Jaramillo, 2014, p. 3).

La memoria, como transformadora, posibilita situar a las comunidades como sujetos políticos de transformación social y no únicamente desde la identidad como víctimas, teniendo como punto de encuentro el dolor, "una memoria tejedora de experiencias, en la que importa el recuerdo como un "acto ética y políticamente solidario", como un acto transformador" (REDEPAZ, 2014, p. 11). La memoria transformadora involucra a una comunidad en general, que ha sido fracturada en su identidad, en sus proyectos individuales y colectivos, por diferentes consecuencias dejadas a causa del conflicto armado, posibilitando de esta manera la reconstrucción de lazos de confianza y trabajo colectivo, que a su vez les brinda a las comunidades la posibilidad de sanar colectivamente y unir sus voces de cara a un objetivo común como la reconstrucción del tejido social en sus territorios.

Acciones que se pueden enmarcar en la categoría de capacidades políticas, entendiendo las mismas como "La posibilidad de transitar hacia una sociedad más dispuesta al diálogo, la movilización pacífica y la convivencia demanda la creación de capacidades colectivas e individuales necesarias para construir una democracia más sustantiva" (Cifuentes,2016, p 11). Es así como la IAP (Investigación Acción Participante) no solo moviliza las capacidades políticas de forma participativa, sino que permite una reciprocidad al reconstruir mediante el diálogo intergeneracional la colaboración y el cuidado de nuevos imaginarios y recuerdos de dignidad, empoderamiento e identidad significativos para las relaciones y reconocimiento integral de la historia y vida del territorio.

"Memorias transformadoras porque permite hacer el tránsito de unas memorias que se dedican a registrar, archivar y exhibir el dolor, a unas memorias que ayudan a tejer la experiencia temporal, cotidiana e histórica de las comunidades y organizaciones en sus dimensiones integrales" (REDEPAZ, 2014, p. 12); no debe estar centrada en los hechos victimizantes de las comunidades, por el contrario, parafraseando a Jelin (2001), se debe sentir, pensar y hacer procesos de construcción de memorias en plural, para aportar a la transformación y reconstrucción del tejido social fragmentado como un acto político.

\section{Un fugaz recorrido por los territorios}

Chalán está ubicado entre montañas que constituyen la serranía de los Montes de María, con 4.567 habitantes, con el $51 \%$ de mujeres y $49 \%$ de hombres y el $85 \%$ de la población víctima. (DANE, 2019). Chalán fue nombrado como el primer territorio 
de paz en Colombia, aunque esto solo quedó en papel e incumplimientos por parte del Estado, ya que el abandono es evidente en materia de educación, salud, cultura, recreación, saneamiento, etc. Sin embargo, las comunidades han resistido ante la crueldad del conflicto armado que aún ronda por las calles de este territorio.

El tejido social en este territorio está quebrado, la pérdida de la solidaridad y confianza entre sus habitantes es una de las consecuencias del conflicto armado que sacudió lo más profundo de las relaciones sociales. La memoria ha parecido desvanecerse entre los relatos de los chalaneros; el burro bomba, los asesinatos selectivos y las masacres solo reposan en las historias de quienes lo vivieron, y que llevan atrancado en su garganta y su corazón, y en su gran mayoría sin poder narrar o expresar los inclementes hechos que pasaron.

Habitando las calles, quienes han vivido por la historia del municipio de Chalán resaltan en medio de narrativas la importancia de la construcción de memorias, para que las nuevas generaciones se apropien de sus realidades, de la identidad de un contexto con una carga histórica de luchas y resistencias en medio de la violencia, la irrupción de grupos armados, la corrupción y el abandono estatal. Como lo expresa un guardián de la memoria ${ }^{32}$, del municipio de Chalán, "Ahora los jóvenes no conocen de la historia de Chalán, es importante que se interesen por saber más, porque así pueden ayudar a que por acá no volvamos a sufrir la guerra" (García, L, comunicación personal, 2 de septiembre de 2019).

Por otro lado, hablar de un territorio como es el municipio de Ovejas Sucre, es aprender de momentos e historias hiladas entre voces que se describen así: "Ovejas es un lugar lleno de alegría, música, baile, gaitas, cosechas y gente linda, pero también ha sido víctima de la violencia, del dolor, la desesperanza, el olvido y la mala administración de líderes que no piensan 'na má' en ellos" (Barreto M, comunicación personal, 22 de mayo de 2019).

Ovejas es un municipio que, aunque pertenece al departamento de Sucre, en las conversaciones con sus habitantes, ellas y ellos, al igual que chalaneras y chalaneros, se reconocen del territorio de Montes de María, subregión que acoge con sus mantos verdes y fértiles quince municipios, siete de Bolívar y ocho de Sucre. Según las proyecciones del DANE para el año 2019, el municipio de Ovejas cuenta con un total de 20.846 personas, en la cabecera municipal residen 12.057 habitantes y 8.789 en la zona rural.

Debido a su posición geoespacial estratégica, ha sido un territorio históricamente situado en medio de conflicto armado y las rutas controladas por el narcotráfico. Diferentes grupos al margen de la ley (FARC frente 35 y 37 y paramilitares del Bloque Héroes de Montes de María) perpetuaron durante varios años infames hechos y múltiples violaciones a los derechos humanos: masacres, detenciones arbitrarias, extorsiones, desplazamientos forzados, desapariciones forzadas, asesinatos selectivos, entre otros hechos victimizantes. Estas acciones bélicas y deshumanizantes dejaron el tejido social fracturado, con un total de 17.787 víctimas que oficialmente han sido incluidas en el RUV (2019). 
Chalán y Ovejas, territorios habitados por cuerpos, lenguajes y paisajes que han sido silenciados y afectados cruelmente por la indiferencia de la guerra, comunidades que no han dejado de soñar: antes, durante y después del conflicto, tejiendo capacidades políticas para organizarse, participar, visibilizarse, indignarse y alzar la voz frente a las violaciones a los derechos humanos.

Desde el reconocimiento de capacidades políticas frente a las resistencias cotidianas construidas desde la base local de las comunidades emerge la necesidad de co-construir memorias transformadoras, a través del arte político y expresiones simbólicas, que permitan volver hacia los relatos de dolor y el horror, pero con una intención no solo de sanar y recordar, sino de reconocer la diversidad de resistencias que frente al olvido y la violencia ha construido individual y colectivamente la comunidad.

Hacer posible, además, que estos relatos, rostros y voces sean visibilizadas y generen inquietudes, preguntas y reflexiones en un país que se resiste a recordar a quienes no están, pero que, más aún, se resiste a reconocer las apuestas, ideas y esperanzas de los que están y construyen paz cotidianamente.

\section{El arte como movilizador de sentires políticos}

Los territorios de Chalán y Ovejas están cobijados por los Montes de María, Serranía de San Jacinto, cultura de gaitas, porros y bullerengues, debido a la tradición oral que ha sido trasmitida en medio de acordes y bailes típicos. El arte político, que abarca diferentes expresiones artísticas, es la estrategia metodológica que acompaña la presente investigación.

El arte como movilizador de sentires en los territorios de Montes de María es entendido como puente para el reconocimiento y la visibilización de las expresiones de resistencia, de lucha, las fortalezas y los anhelos. El arte tiene la capacidad de incidir socialmente; es allí, en el espacio público, el cual denominamos como lugares vivos, entendidos como la construcción colectiva e intergeneracional de lugares vitales, cargados de significados que den cuenta de las memorias tejidas desde la pluralidad.

Así pues, el arte, en este caso, no se reduce a expresiones concretas y lugares de exhibición; el arte, por el contrario, se teje desde la cotidianidad, desde las entrañas, desde aquello que hace vibrar frente al mundo y las múltiples realidades que en él convergen, permitiendo hacer diversas lecturas sobre una misma expresión, desde los contextos en los cuales se interpreten, por ello el arte no debe ser el privilegio de unos pocos.

El arte mismo es transgresor en la cotidianidad, creado desde las bases locales, permitiendo que estas exhiban sus intereses, sus necesidades, sus anhelos y sus sueños. Hablamos del arte político como herramienta movilizadora, mediadora y sanadora en las comunidades, ya que permite construir colectiva e individualmente nuevas formas posibles de habitar el mundo, de hacer visible lo que no se puede hablar y escuchar, de expresar mediante otros lenguajes no indecible e invisible, muchas veces por la represión de un contexto que vulnera las libertades fundamentales del ser humano. 
Por otro lado, el arte, desde lo político, construye y visibiliza capacidades inexploradas o inconscientes en los individuos y comunidades, permitiendo así un fortalecimiento de las ya existentes y de las cuales no se reconocían.

\section{Metodología}

En concordancia con lo anterior, la IAP hoy día es una metodología ético - política e históricamente responsable con la transformación de contextos que vulneren los derechos humanos en las comunidades. Es por eso que, más allá de la producción colectiva de conocimientos académicos, nos interesa la investigación como proceso crítico, reflexivo y generador de sentidos políticos y éticos en la realidad social. Lo que nos interesa con la IAP es generar procesos de formación y acompañamiento a los participantes como sujetos de conocimiento, quienes a su vez conocen sus derechos, reconocen sus capacidades, comprenden sus realidades, visibilizan sus resistencias, enfrentan sus éxodos, asumen sus deberes ciudadanos, las creaciones, las resiliencias, las organizaciones y los colectivos que recrean constantemente la cotidianidad para permitirse sobrevivir y resistir en un país en medio de la guerra.

La finalidad no se agota en la producción de conocimientos, sino que involucra, también, la construcción participativa, con base en ellos, de transformaciones sociales, en este caso, transiciones orientadas a la reconciliación y a la construcción de paz territorial estable y duradera.

Por ello, la presente Investigación Acción Participativa se desarrolla con un equipo intergeneracional denominado como Guardianas y guardianes de la memoria, construyendo alternativas artísticas para el tránsito de unas memorias victimizantes al reconocimiento de capacidades agenciadas por las mismas comunidades de cara al tránsito en el que se encuentra inmerso Colombia.

La pertinencia de entretejer un grupo intergeneracional para la construcción de memorias plurales nace de la importancia del reconocimiento de los saberes ancestrales que han sido trasmitidos de generación en generación y que son trasmitidos a modo de historias, anécdotas, cuentos, canciones y décimas (poemas cantados) que permiten que las nuevas generaciones apropien sus historias y aporten desde sus contextos a la reconstrucción de tejido social en sus territorios.

La metodología utilizada engloba la observación participante en estos espacios territoriales, la vivencia en las unidades familiares, las conversaciones cotidianas y casuales, las entrevistas en profundidad a habitantes de Chalán y Ovejas y diferentes técnicas como grupos focales, diarios de campo, audiovisuales, como el análisis de fotografía y video realizado en el transcurso de la investigación, que nutre y complementa el análisis de discurso, así como la exploración de fuentes secundarias, sobre todo los discursos de los medios de comunicación convencionales y no oficiales, informes, planes de desarrollo, datos cuantitativos.

\section{Hallazgos}

Evocar memorias y tejer el tránsito hacia la trasformación y comprensión de las capacidades gestadas en medio del conflicto armado implica en un primer momento 
rememorar los recuerdos, para así reconocer las capacidades que permitieron a los sujetos sobrevivir y resistir, desde las acciones políticas que en medio del contexto de opresión pudieron ejercer.

\section{El silencio ante el ruido de la guerra}

Emerge el silencio como una capacidad política de sobrevivencia frente a la violencia, este silencio relacionado a la capacidad de ser neutral en medio de diferentes actores armados que convergían en los territorios; como lo expresa una de las guardianas de la memoria en uno de los encuentros intergeneracionales "Por allá en los dos mil cuando la violencia azotó los Montes de María, nos tocaba no ver, no escuchar, no decir nada, esa fue nuestra manera para sobrevivir" (García. Comunicación personal, 22 de agosto de 2019).

El carácter de capacidad política atribuido a silencio está asociado a la casi que obligación de resistir mediante la toma de múltiples decisiones para preservar y proteger la vida. Por otro lado, se concibe como una apuesta política por parte de las comunidades frente al contexto del conflicto armado, ya que, en la actualidad, algunos habitantes de los municipios de Chalán y Ovejas han venido construyendo iniciativas para la reconstrucción social de cada uno de sus territorios, generando a su vez la consolidación de nuevas capacidades políticas desde sus cotidianidades, pasando de ser resistencias cotidianas individuales a tejerse desde lo colectivo, para en un fin último construir desde lo comunitario los sueños de territorios en paz.

Si bien los silencios pueden asociarse con impedimentos de habla, no puede negarse su carácter estratégico, tanto en situaciones donde aún prevalece la violencia y la represión, como también, y de manera muy importante, en la apropiación y subjetivación de las experiencias de dolor; en las formas en las que los sujetos, individual, familiar y colectivamente tramitan el dolor. Por ello, es posible decir que los silencios en el lenguaje se manifiestan bajo múltiples expresiones, en el modo en que rehabitamos los espacios de la devastación. (López, 2015, p. 154)

El silencio está relacionado a un principio de autocuidado, en un contexto culturalmente estrepitoso; guardar la palabra y la canción fue un reto que le permitió a las comunidades sobrevivir. Pero ahora vivimos en un periodo en el cual se hace inminente la construcción de alternativas políticas que aporten a la reparación colectiva de las comunidades que han sobrevivido y resurgido de entre el estigma, el olvido y la violencia, desde la circulación de la palabra y la tramitación de dolores.

\section{La religión como congregación para la resistencia comunitaria}

En la construcción del reconocimiento de resistencias colectivas y comunitarias está mediada por técnicas metodológicas como cartografías sociales, narrativas visuales desde murales comunitarios, teatro del oprimido. Para la construcción comunitaria de los lugares vivos, diversas expresiones artísticas contribuyen a este propósito, 
una de ellas es la circulación de la palabra, esto por medio de narrativas, cuentos, chistes, canciones, poemas; estas expresiones hacen parte de la cotidianidad de las comunidades de Chalán y Ovejas, ya que la oralidad es una puntada que llena de vida a los pobladores, siendo la palabra el común encuentro de relatos de resistencia y esperanza.

La exposición de lo visible y no visible busca plasmar por medio de expresiones artísticas como la pintura y el teatro, las historias narradas y vividas por la comunidad que tributan a la reconstrucción del tejido social en sus territorios, en sus cotidianidades. En la construcción de alternativas para exponer lo visible y no visible de las memorias transformadoras y las historias de resistencia emerge una propuesta por parte del grupo de guardianas y guardianes de la memoria, de la construcción de obras de teatro, potenciando las expresiones artísticas y culturales que se han construido desde las corporalidades montemarianas.

Es por ello que "La perspectiva de una espiritualidad que va acompañada de estructuras religiosas reinventa la capacidad de encontrar felicidad, porque implica conjugar las necesidades del espíritu con las demandas de la religión. Una vez más se teje la relación: Religión, Espiritualidad, Humanidad" (Palacio, 2015, p. 467). La incertidumbre, la desesperanza, el olvido, el dolor y la muerte no pasan sin causar un profundo cambio en las subjetividades y sentidos, por eso, la demanda del espíritu de encontrar un qué, por qué y para qué, y es en la religión donde esa urgencia existencial calma la sed. En territorios marcados por el conflicto armado y múltiples conflictividades, la religión toma mayor fuerza, pues es en ella el lugar donde se convive con otros, ya que sin congregación no hay templo; también es la certeza de contar con un mejor mañana, es la fe y la esperanza de que las cosas podrían ser mejor. Lo anterior puede verse reflejado en uno de los relatos:

Ahora soy una persona diferente, no soy el mismo de antes... que hacía cosas malas, que digo yo que son malas pequeñas, pero son malas de todas maneras, he dejado de hacerlas, he tenido un encuentro con Dios y en sus palabras me habla mucho que Dios es amor, tanto que Él entregó su vida por amor a nosotros. Entonces, yo me he dedicado a demostrar ese amor que está en mí, porque si Dios es amor, tú también eres amor, entonces me he dedicado a demostrar ese amor a las personas y quiero seguir mejorando, me pone triste algo, que a veces le digo a Dios en mis oraciones: "Dios, quisiera ayudar más, pero no puedo señor", porque te digo una cosa, la Biblia dice que son muchas las personas que uno tiene que demostrarle que todavía vivimos en amor, que Dios es Amor y son muchas las personas por ayudar, en su palabra, Él dice "es más bienaventurado dar que recibir”. (G. Cortés, comunicación personal, 5 de septiembre de 2019)

La espiritualidad en la religión son elementos casi que insuperables en la búsqueda constante de fortaleza, esperanza y unión colectiva. Aquí es donde la resistencia no es la sublevación al poder ni es fuerza, pero sí es la posibilidad desde la sensibilidad de crear otros valores y sentidos a la vida. 


\section{Al son de gaita y tambor: resistiendo entre melodías}

Desde los encuentros intergeneracionales con guardianas y guardianes de la memoria en los municipios de Chalán y Ovejas ha emergido entre conversaciones y expresiones artísticas como la música, la fuerza que impulsa a reconstruir los lazos comunitarios. En las melodías de Adolfo Álvarez emergen los anhelos de vivir en paz, de contar con un Chalán en el que sus derechos, junto a su dignidad, son reconocidos en pluralidad. La siguiente canción emerge como una creación colectiva que pretende transmitir los anhelos de paz de territorios que históricamente ha sido afectado por el conflicto armado, pero que su comunidad decide renacer

\section{I}

Abrazada al azul cielo que acompaña

El verde de las montañas en Chalán

Con sus fuentes cristalinas, ojos de agua

La esperanza de la gente al caminar

\section{CORO}

Quiero amar, construir caminos de paz

Y pintar ese cielo grande como el mar

Revivir las memorias que nos vieron avanzar

Ser feliz al verte un día cambiar

\section{II}

Que lo injusto no me sea indiferente

Dios me ayude a construir comunidad

Ver sus luchas, resistencias permanentes

Para colectivamente mejorar

\section{III}

Los caminos quebrados de la guerra

Lastimaron el alma de aquel día

Hoy te invito a resurgir en melodías

Con los libros, la música y poesía.

La melodía no solo remite a un pasado conocido, el cual se reconoce con sus secuelas, memorias y experiencias; también traslada la voz hacia un futuro en el cual está presente la añoranza de construir paz. De ahí que la música haga parte de lo que Scott (2011) ha denominado formas cotidianas de resistencia, pues son en las experiencias y las acciones en las prácticas culturales, donde está la riqueza de encontrar la fuerza simbólica que tiene lo cotidiano para transformar. 
El carácter transformador de la memoria supone tejer puentes entre las esferas públicas y privadas del dolor para dar paso a nuevas posibilidades de habitar el territorio. En los relatos, por ejemplo, Adolfo hace alusión a "revivir las memorias que (les) nos vieron avanzar", haciendo evidente la permanencia de un colectivo, un entre nos, como lo define Hanna Arendt, un lugar de la memoria que involucra a otros y que exige volver sobre lo que les permitió seguir para así transitar hacia la justicia social, la dignidad humana y el cumplimiento de los derechos humanos. "La experiencia no se limita solo en qué le pasa a uno, sino lo que uno hace con lo que le pasa" (Redepaz, 2007, p. 12); ese quehacer con los hechos que pasan suponen un proceso individual y colectivo de las comunidades, el cual debe incluir el reconocimiento como sujetos políticos de cambio que aportan a sanar las heridas que hay, permitiendo que la reconstrucción de la memoria sea un proceso intergeneracional, reivindicando la lucha pacífica y digna de quienes ya no están y cimentando bases fuertes para la no repetición de la mano de una reparación colectiva, integral y profunda que escuche la voz de las comunidades.

\section{Conclusiones}

El proceso de transición actual exige volver sobre los recuerdos y las memorias que aún permanecen en el silencio, un silencio que es político y que nos habla del horror de lo ocurrido, de los miedos y marcas dejadas por el conflicto armado; sin embargo, esos silencios también han sido irrumpidos por gritos de esperanza, manos de paz y cuerpos en resistencia, que permean desde sus cotidianidades hasta sus expresiones y sentidos de vida.

Reconocer capacidades políticas frente a la resistencia desde las cotidianidades de las comunidades implica reconocer la riqueza de los diálogos generativos y trasformadores, que son enunciados desde diferentes expresiones artísticas en espacios públicos hasta los silencios como acto político y de autocuidado frente la vida, así como lo narra una guardiana de la memoria "Ahora es que narramos para sanar, pero antes para poder vivir teníamos que estar en silencio, hacer de cuenta que nada pasaba" (Sequea, S. Conversación personal, 19 de Julio). Por ello, la importancia de narrar desde recuerdos políticos y transformadores y de manera intergeneracional en aras de aportar a la no repetición de hechos victimizantes en los territorios.

Hablar de unas memorias transformadoras exige que se tenga un enfoque diferencial e intergeneracional, ya que las resistencias como capacidad política han sido creadas desde las mujeres, poblaciones campesinas, diversidades sexuales y de género y poblaciones étnicas, hasta las diferentes generaciones, resistiendo desde la siembra, la danza, la música, el teatro y la pintura, la religión, desde sus expresiones diferenciales reconociendo los múltiples saberes y sentires que convergen.

Se debe abrir la posibilidad de ir de una concepción del arte pensado desde los espacios "contemporáneos o internacionales", dados en las grandes ciudades capitales, a pensar el arte desde las esferas comunitarias y locales, en el que confluyan expresiones simbólicas que creen sentidos transformadores y que resignifiquen el recuerdo como acto político, irrumpiendo así en la cotidianidad de las comunidades, mediante la apropiación de espacios púbicos para la construcción de lugares vivos donde circule la palabra, la narrativa y la memoria desde diferentes estrategias artísticas y políticas construidas por las comunidades, cargadas de simbolismos y sentires, tejidos 
comunitariamente, generando espacios de reflexión y emancipación colectiva desde la reconstrucción de lazos de solidaridad y confianza.

La pertinencia de la producción de conocimiento desde la academia exige el trabajo permanente con la comunidad; se hace necesaria la permanencia en los territorios desde el compromiso ético - político con las comunidades de reconocer sus acciones locales de reconstrucción del tejido social y reparación, visibilizando sus intereses y necesidades desde su sentir - pensar en su relación con el territorio y la construcción de relaciones con las comunidades. La construcción de proyectos articulando la voz de la comunidad y la academia (IAP) exige un enfoque de acción sin daño con las comunidades, siendo responsables políticamente con la seguridad y la no revictimización de las comunidades.

Las diferentes apuestas construidas y apadrinadas desde el Estado resultan pertinentes en el proceso de reconstrucción del tejido social en diferentes zonas históricamente afectadas por el conflicto armado, así como su divulgación en la sociedad en general $\mathrm{y}$ ante diferentes organizaciones o instancias que se pudieran articular a las mismas.

A modo de reflexión, la reconstrucción del tejido social debe ser un asunto que corresponda a la sociedad en general; es un proceso dinámico y es necesario sacarnos de las diferentes zonas de confort, como lo son las academias, las entidades gubernamentales, la ignorancia y la indiferencia, reconociendo así otras maneras de habitar el mundo, como lo hacen las campesinas y los campesinos que residen en las periferias del territorio, aportando al proceso de transición y reconstrucción en el que se encuentra el tejido social en Colombia desde las acciones cotidianas como el diálogo, la participación, la ciudadanía activa y la confianza que se construyen en las relaciones sociales entre actores sociales.

\section{Referencias}

Águila, E. (2012). Sacar la voz: Tomarse la palabra, de silencios y resistencias. Red Chilena contra La Violencia Doméstica y Sexual, p: 7-12.

Alcaldía de Chalán (2016) Plan de desarrollo 2016-2019 Chalán somos todos. Acuerdo social para la generación de oportunidades. Disponible en: http://www.chalansucre.gov.co/planes/plan-de-desarrollo-20162019

Alcaldía de Ovejas (2000). Esquema de ordenamiento territorial 2000, 2001. Disponible en: http://cdim.esap.edu.co/BancoMedios/Documentos\%20PDF/ ovejassucreeot2000.pdf

Alcaldía de Ovejas, Sucre (2018) Oportunidades para la Paz y el Buen Vivir 2016 2019. Alcaldía de Ovejas Sucre. Disponible en http://www.ovejas-sucre.gov.co/

Barrera Negrete, V. (2013). La investigación- acción participativa en Córdoba. Seminario "Orlando Fals Borda y la IAP". Montería, Colombia. Disponible en https://www. youtube.com/watch?v=qjPZs1kIkTw 
Boal, A. (2001). Juegos para actores y no actores. Editorial Alba: S.I.U

Cancimance López, Andrés (2015). Los silencios como práctica de resistencia cotidiana: narrativas de los pobladores de El Tigre, Putumayo. Boletín de Antropología Universidad de Antioquia 30(49), Disponible en: https://www. redalyc.org/articulo.oa?id=557/55740044007 https://doi.org/10.17533/udea. boan.v30n49a07

Capasso, V. (2018). Arte, polítca y espacio: Una propuesta de analisis desde la teoria de Chantal Mouffe. Alpha, 253. 268. https://doi.org/10.32735/S0718220120180004700180

Capasso, V. C. (2018). Lo político en el arte. Un aporte desde la teoria de Jacques Ranciere. Estudios de filosofia, 216-235. https://doi.org/10.17533/udea. ef.n58a10

Cifuentes, Patiño. (2016). Proyecto de reconstrucción del tejido social (Documento inédito). Universidad de Caldas: Manizales.

DANE. (s,f) Proyecciones nacionales y departamentales de población 2005-2020. Recuperado de http://www.dane.gov.co/reloj/.

Galeano, E. (2012). Los hijos de los días. Uruguay.

Honneth, A. (1997). La lucha por el reconocimiento. España.

Jaramillo, J. (s,f). De las memorias de la victimización a las memorias transformadoras en Colombia. Provocaciones y Desafíos. Pontificia Universidad Javeriana: Bogotá

Jaramillo, J. (2014). Apuntes peregrinos sobre la categoría de memoria. Cesycme, 2.

Jelin, E. (2001). De qué hablamos cuando hablamos de memorias. En los trabajos de la memoria. España: Siglo Veintiuno Editores.

Jelin, E. (2002). Los trabajos de la memoria. Madrid: Siglo XXI Editores. Recuperado de http://www.centroprodh.org.mx/impunidadayeryhoy/DiplomadoJT2015/ Mod2/Los\%20trabajos\%20de\%20la\%20memoria\%20Elizabeth\%20Jelin.pdf

López, A. (2015). Los silencios como práctica de resistencia cotidiana: narrativas de los pobladores de El Tigre, Putumayo, que sobrevivieron al control armado del Bloque Sur de las AUC. Boletín de Antropología Universidad de Antioquia. Recuperado de https://www.redalyc.org/articulo.oa?id=55740044007

Nussbaum, M. (2002) Mujeres y el Desarrollo Humano: el enfoque de las capacidades. Universidad de Cambridge: Barcelona, España

Nussbaum, M. (2012) Crear capacidades. Editorial Paidós

Molina, N. (2004). Athenea Digital. Revista de pensamiento e investigación social. Obtenido de https://atheneadigital.net/article/view/n6-molina/175-html-es 
Molina, N. (2005). Resistencia comunitaria y transformación de conflictos. Derechos Humanos y conflicto , 71- 82.

REDEPAZ (2014). Propuesta conceptual alrededor de la construcción del concepto de memoria. Pontifica Universidad Javeriana.

Scott, J. (2000). Los dominados y el arte de la resistencia. Discursos ocultos. México: Ediciones Era.

Tello, F. H. (2011). Las esferas del reconocimiento en la teoría de Axel Honneth. Revista de Sociología , 45-57.

Plan de Desarrollo 2016-2019 “Chalán somos todos. Acuerdo social para la generación de oportunidades".

Plan de desarrollo del municipio de Ovejas "Oportunidades para la paz y el buen vivir". 2016-2019.

Plan de desarrollo departamento de Sucre: "Sucre progresa en paz", y Chocó: "Oportunidades para todas las subregiones". 2016-2019.

Registro Único de Víctimas http://rni.unidadvictimas.gov.co/ 1 de junio de 2018

Universidad de Caldas. (2016). Hilando capacidades políticas para las transiciones en los territorios. Programa: reconstrucción del tejido social en zonas de posconflicto. Colombia Científica.

Zubiria Samper, S. (2013). Investigación-acción y epistemologías del Sur. Conferencia presentada en la Cátedra Orlando Fals Borda en la Universidad de Nariño, Bogotá, Colombia. Disponible en https://www.youtube.com/watch?v=IyKekZISnUY 